From the American

Board of Family Medicine

Ann Fam Med 2016;14:485-486. doi: 10.1370/afm.1979.

\section{AMERICAN BOARD OF FAMILY MEDICINE ELECTS NEW OFFICERS AND BOARD MEMBERS}

The American Board of Family Medicine (ABFM) is pleased to announce the election of 4 new officers and 3 new board members. The new officers elected at the ABFM's spring board meeting in April 2016 are: Keith L. Stelter, MD, of Mankato, Minnesota elected as Chair, Elizabeth G. Baxley, MD, of Greenville, North Carolina as Chair-Elect, Christine C. Matson, MD, of Norfolk, Virginia as Treasurer, and Montgomery Douglas, MD, of Farmington, Connecticut as Member-at-Large, Executive Committee. In addition, the ABFM welcomes this year's new members to the Board of Directors: Wendy Biggs, MD, of Overland Park, Kansas; Christopher A. Cunha, MD, of Crestview Hills, Kentucky; and Michael K. Magill, MD, of Salt Lake City, Utah.

The following new ABFM officers will each serve a 1-year term:

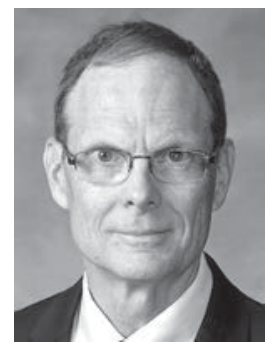

Dr Stelter is the Associate Director of the Mankato Family Medicine Residency Program in Mankato, Minnesota and an instructor with the Rural Physician Associate Program of the University of Minnesota Medical School. He maintains an active clinical practice in hospital, clinic, and nursing home set-

tings. Dr Stelter will serve the ABFM on the Executive Committee as its Chair.

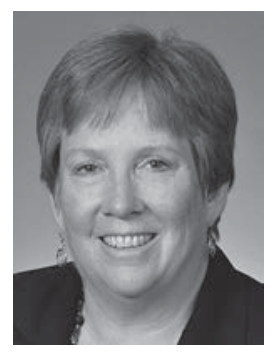

Dr Baxley is a Professor of Family Medicine and Senior Associate Dean for Academic Affairs at the Brody School of Medicine at East Carolina University, where she has served since 2012. Before joining the faculty at Brody, she spent 18 years at the University of South Carolina School of Medicine, serving as Residency Director, and later as Chair, of the Department of Family and Preventive Medicine.
Dr Baxley will serve the ABFM on the Executive Committee, the Bylaws Committee, the Credentials Committee, the Examination Committee, the Audit/ Finance Committee, the Research \& Development Committee as its Chair, and the Certification Committee.

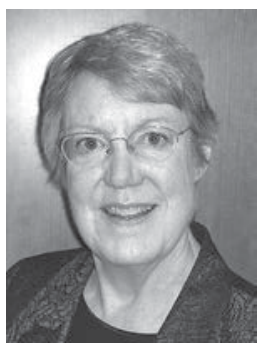

Dr Matson is Professor and Chair of the Department of Family and Community Medicine at Eastern Virginia Medical School. She has served as Associate Dean for Education, Director of the Family Medicine Residency Program and Co-Director of the Family Medicine/Internal Medicine Combined Residency Program in Norfolk, Virginia. Dr Matson will serve the ABFM on the Executive Committee, the Bylaws Committee as its Chair, the Credentials Committee, the Examination Committee, the Audit/Finance Committee as its Chair, the Research \& Development Committee, the Communications/Publications Committee, and the Certification Committee.

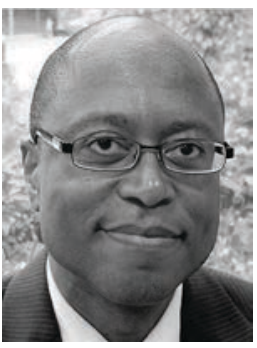

Dr Douglas is Chair of the Department of Family Medicine at the University of Connecticut School of Medicine and Saint Francis Hospital and Medical Center. He previously served as Chairman of the Department of Family and Community Medicine and Associate Dean for Diversity and Inclusion at New York Medical College. Dr Douglas will serve the ABFM on the Executive Committee, the Bylaws Committee, the Credentials Committee, the Operations Committee, the Audit/Finance Committee, the Research \& Development Committee, and the Certification Committee as its Chair.

The ABFM welcomes 3 new members to the Board of Directors:

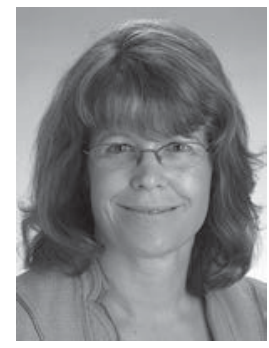

Dr Biggs is an Associate Professor and the Family Medicine Residency Program Director at the University of Kansas Medical Center. She is on the Board of Directors of the Kansas Academy of Family Physicians and serves on the Graduate Medical Education Committee for the Society of Teachers of Family Medicine. Dr Biggs will serve the ABFM on the Credentials Committee and the Certification Committee. 


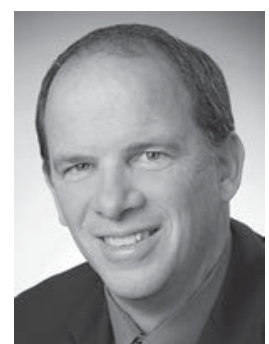

Dr Cunha is the co-founder of Pediatric Associates, PSC in Crestview Hills, Kentucky, and also served for 18 years as Managing Partner. He has served on the Board of Directors of the American Board of Pediatrics since 2012, currently serving as Chairman, and has served as Chairman of the Tristate $\mathrm{PHO}$ at Cincinnati Children's Hospital since 2007. Dr Cunha will serve the ABFM on the Examination Committee and the Communications/Publications Committee.

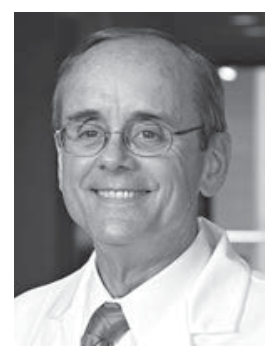

Dr Magill is Professor and Chairman of the Department of Family and Preventive Medicine at the University of Utah School of Medicine and serves as Director of the Utah Area Health Education Centers Program at the University of Utah. He previously served for 10 years as Executive Medical Director of the University of Utah Hospitals and Clinics/Community Physician Group. Dr Magill will serve the ABFM on the Operations Committee and the Research \& Development Committee.

The remaining current members of the Board are: John Brady, MD, of Newport News, Virginia, Colleen Conry, MD, of Aurora, Colorado; Joseph Gravel,

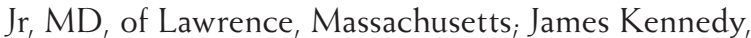
MD, of Winter Park, Colorado; Jerry E. Kruse, MD, $\mathrm{MSPH}$, of Springfield, Illinois; Lorna Anne Lynn, MD, of Philadelphia, Pennsylvania, David W. Mercer, MD, of Omaha, Nebraska, Marcia J. Nielsen, PhD, MPH, of Washington, DC, Robert J. Ronis, MD, MPH, of Cleveland, Ohio; David E. Soper, MD, of Charleston, South Carolina; and Melissa Thomason of Pinetops, North Carolina.

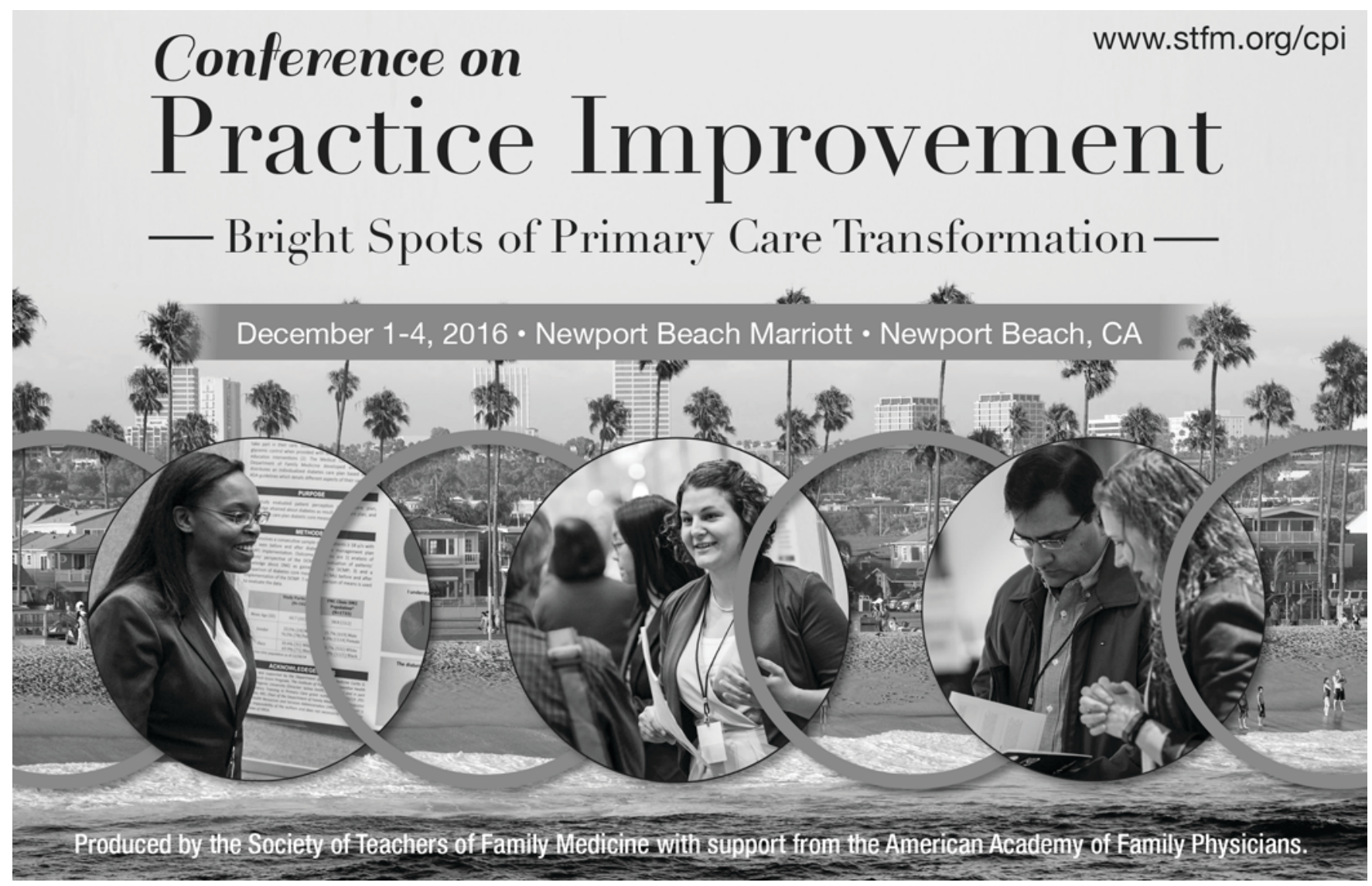

ANNALS OF FAMILY MEDICINE + WWW.ANNFAMMED.ORG + VOL. 14, NO. 5 + SEPTEMBER/OCTOBER 2016 